\title{
INVESTIGACIÓN, VALOR Y CRÍTICA
}

\author{
Manuel González de Ávila
}

1. El paradigma de investigación semiótica que fue en buena medida responsable del éxito de la disciplina durante las pasadas décadas, su modelo estructural-inmanente, poseía la optimista seguridad de ser una rigurosa práctica científica, a salvo de cualquier filtración ideológica. La semiótica estructural-inmanente, profesando una epistemología de raíces lógico-matemáticas, relativa y arbitraria en sus bases — sus axiomas-, se presentaba como saber en contrucción deductiva ajeno a toda afirmación de «sustancias» (Courtès, 1976: 39; Ruprecht, 1984: m 6). Sin embargo, la propia potencia interna de su enfoque deductivo acabó por empujar a la teoría semiótica inmanente hacia una deriva esencialista. Los textos que analizaba parecían desarrollarse por milagrosa necesidad a partir de la antedicha axiomática sintáctico-semántica; en esa necesidad pronto dejó de verse un acto de fabricación científica, un encadenamiento de hipótesis lógicas in-sustanciales, para percibirse el despliegue fidedigno de las propiedades inherentes al texto; $y$, poco después, los enunciados que articulaban las propiedades textuales se cargaron de un contenido no ya sólo lógico, sino también ontológico, de modo que pretendieron poder captar al mismo tiempo los rasgos del ser y los de su representación semiótica (Petitot, 1985: 123; 1987: 180-197). De donde 
se seguía que, en cuanto enunciados lógicamente verdaderos y ontológicamente fundados, las proposiciones de la semiótica inmanente no dependían del sujeto que las formulaba, el cual sólo era el instrumento transparente e ingrávido de la formulación de su verdad esencial. La semiótica inmanente no tenía entonces más que ampliar y rectificar esos sistemas de enunciados para ir afinando una teoría que se autoperfeccionaba en un vacío total de valoraciones subjetivas, esto es, históricas.

2. El conocimiento semiótico estructural-inmanente nada quería deberles ni al sujeto que lo elaboraba ni a la historia donde el sujeto científico actuaba: el saber semiótico, así implantado en la cientificidad pragmáticamente arrealista y ontológicamente hiperreal de la teoría inmanente, y contra las declaraciones «constructivistas» de sus valedores, semejaba un puro producto advenido sin necesidad de que en su advenimiento se hubiera realizado ningún gesto de producción, ningún trabajo humano.

3. Un buen número de autores de tendencia historicista y sociológica han encontrado indefendible este férreo logicismo ontológico de la última semiótica estructural-inmanente. Su epistemología es bien distinta: contra la táctica de autonomización del saber propia de la semiótica inmanente, aquéllos recuerdan que los conocimientos científicos son parte inalienable de un proceso histórico global sobredeterminado por múltiples factores, con relación a los cuales sólo puede la ciencia lograr cambiantes grados de independencia (Pêcheux, 1975: 171; Jameson, 1989: 34). Consecuentemente, todas las ciencias, las «exactas» no menos que las «humanas», se desenvuelven en un universo social presidido en principio por las leyes de la oferta y de la demanda, y están sometidas a criterios de rentabilidad económica y simbólica - la última, no por ardua de medir menos real ni imperativaDesgajar el campo de la producción científica del resto de los campos de la producción social, sin mayores explicaciones ni razonamientos, equivale a formular una suerte de hiperbólica petición de principio, supuestamente fundadora de la neutralidad del discurso de ciencia. Pero el discurso científico, pese a la petición de principio deshumanizadora de la semiótica inmanente, es el producto de grupos de sujetos, grupos tanto interiores al campo de producción científica - los colegios de especialistas - como exteriores a él — las instituciones y organismos que subvencionan la investigación-. Y los grupos interiores y exteriores que gestionan la labor de la ciencia son grupos sociales precisamente porque se estructuran en torno a intereses comunes y a puntos de vista compartidos, los cuales no pueden no introducirse en las prácticas científicas ni dejar de articularlas en cierto grado (Zima, 
1984: c12). Es la lucha y la contradicción entre tales grupos, y entre los diferentes criterios que sostienen, lo que actúa como catalizador del pensamiento científico: sin el antagonismo de los intereses, particulares y colectivos, que en él se enfrentan incesantemente entre sí, el campo de la ciencia hubiera engendrado sólo teorías homogéneas; o mejor, no hubiera engendrado sino una teoría, lo que también en este caso sería lo mismo que ninguna teoría (Bourdieu, 1976: 99).

3. La historicidad de los grupos que promueven y hacen la ciencia determina la historicidad de la ciencia misma, o por lo menos una de sus dimensiones históricas. La historicidad de la ciencia, sin embargo, no es exclusivamente la que en ella inyectan sus sujetos colectivos. La semiótica metadiscursiva, al igual que la práctica social discursiva que investiga, es una actividad productora de sentido. Y la producción semántica únicamente se realiza dentro de un continuo histórico-genealógico que aporta los materiales para elaborar el sentido, que ordena el decir, científico o ideológico, siempre desde lo ya dicho, aunque el decir sincrónico no sea ya exactamente identificable con la diacronía de lo dicho. Los hombres no pueden ir al encuentro del mundo en completa y disponible ignorancia; no hay estado de naturaleza o de inocencia epistemológicas (Pêcheux, 1975: 172). Las formas del «conocimiento empírico» y las teorías «descriptivas» ponen siempre en juego objetos temáticos previos, materias primas gracias a las que se genera más conocimiento y que tienen una historia y un desarrollo propios y desiguales. La inexorable filiación histórica del saber se troca aquí en inexorable filiación ideológica, a poco que tomemos en serio una definición materialista de la ideología: lo ideológico en un discurso, incluido el de la ciencia, es el sistema de las relaciones que el discurso mantiene con sus condiciones productivas, de las que no se necesita añadir que son históricas (Verón, 1984: 141; 1987: 14, 23). Lo cual se hace particularmente evidente en el subcampo de las ciencias sociales, donde toda teoría opera una selección ideológica de hipótesis y de postulados que más tarde proyectará sobre la experiencia real, para procurar allí verificarlos. Quienes se esfuerzan por borrar, por arrancar de raíz, en una teoría científica cualquiera, dicho conjunto de decisiones ideológicas, ponen de manifiesto que no ha servido de gran cosa el desdichado episodio de la paloma que Kant una vez soltara, aquella paloma que proyectó volar más rápido eliminando el aire que sostenía su vuelo '.

1 No sería justo aprovecharnos del talento fabulístico de Kant después de haber criticado todos los ensayos de kantianizar la semiología: las condiciones a priori de la ciencia, como las de los signos, son empíricas, no transcendentales. Quizá la paloma perdone en nuestro homenaje a su desacierto ejemplar la traición que le hacemos a su dueño. 
4. Ahora bien, las forzosas elecciones ideológicas incrustadas en la teoría son mucho más que simples «ideas», más que presupuestos etéreos sin correspondencia en la realidad. Son, como toda ideología, efectuadoras de realidad, constructoras de la manera en que lo real es definido, clasificado y normativizado por quienes tienen la autoridad epistémica necesaria para hacerlo, los portavoces de la ciencia. Y, si la ciencia dispone del poder de forjar e imponer los estándares con los que se percibe e interpreta lo real, contribuyendo así en mucho a modelarlo, entonces nada resulta menos lógico que hablar de la neutralidad de una ciencia que presuntamente se contentaría con describir la misma realidad que en realidad ella hace. Las ciencias sociales, dice P. Bourdieu, pueden presumir tanto menos de ser autónomas cuanto que su objetivo propio es la representación legítima del mundo social, que cada una procura fabricar e instituir de acuerdo con sus criterios -en el caso de la semiótica, la parcela de representación de lo real que le ha tocado en suerte es fundamentalmente la de los requisitos que han de cumplirse para que los textos, los objetos y las conductas sean sensatos, tengan sentido-. Luego sería un error ver en la imperativa representación de la realidad y de su significado que se constituye en las ciencias sólo un motivo de debate científico: de ella depende, en buena medida, la estabilidad de la entera organización social, de la realidad tal como ésta se encuentra en cada momento articulada por las luchas y conflictos de intereses en el espacio histórico. Y por eso también «la idea de una ciencia neutra es una ficción, y una ficción intencional, que autoriza a tomar por científica una forma neutralizada y eufemística, y en consecuencia muy eficaz simbólicamente, de la representación dominante del mundo social» (Bourdieu, 1976: 101; Passeron, 1991: 89-109). Ignorarlo abonaría en la práctica semiótica un peligroso cultivo de inconsciencia, aquel donde prospera uno de sus mayores enemigos: el afán por simular que se crea saber científico omitiendo el sustrato ideológico de ese saber se dice ntemente científico (Pêcheux, 1975: 111).

5. No queda, por tanto, más remedio que hacerse cargo de que no es posible mantener incomunicadas por higiene, como lo deseaba la teoría estructural-inmanente, a la actividad científica y a esa otra que cabe en general llamar social, o política, o ideológica. El metadiscurso de la semiótica, su análisis de los registros culturales, es una participación ideológica, sea cual sea su fin concreto, en la vida simbólica comunitaria.

6. Esta puesta en tela de juicio de la neutralidad de las investigaciones que se proclaman neutrales se efectúa con frecuencia desde la 
posición de quienes, juzgando inconcebible dicha neutralidad (Bettetini, 1977: 15; Zima, 1984: c12), prefieren reivindicar explícitamente para sus tareas el estatuto de empeño comprometido con el valor. Tal parece ser el caso de toda escritura que añada, al apelativo disciplinar bajo el que se acoge, la incierta calificación de «crítica». Aunque está aún por hacer una genealogía del pensamiento crítico a lo largo de la historia de las ideas, puede no obstante desprenderse lo esencial de sus impulsos de algunas de sus manifestaciones contemporáneas. La crítica, en el sentido que al vocablo le confiere $M$. Horkheimer, es ese género de reflexión sobre los objetos y los acontecimientos sociales en el cual no se olvida la distancia que separa lo que es de lo que podría o debería ser; donde no se confunden lo fáctico, que se legitima a sí mismo por el contundente hecho de ser, y lo posible, a lo que niega la realización de lo realizado, pero que, incluso negado, contiene una superior racionalidad: lo virtual que hubiera sido deseable que se produjese. Si se acepta el principio de que la razón es capaz de distinguir en cada fenómeno su necesidad histórica consumada, su ser-así, y la contingencia de que bien podría haber acontecido de otro modo, puesto que en la gestación de lo fáctico media una serie de decisiones humanas, y que éstas no están siempre tomadas de antemano ${ }^{2}$, entonces la función del pensamiento crítico estriba en negar lo dado, negador a su vez de lo posible, para rebasarlo hacia un horizonte experiencial abierto. La dialéctica es esa forma de proceder que no se limita a constatar los hechos, sino que los interroga, preguntándoles por lo que les falta, por lo que relegaron o destruyeron, y que por eso mismo se ha metamorfoseado en un inconsciente histórico desde el que lo reprimido reclama sin cesar su vuelta a la escena de la historia. «Todo orden que se impongan los hombres bajo la constricción de las condiciones en que estén, toda estructura cultural no menos que todo juicio aislado plantean —queriéndolo o sin quererlo- una pretensión de justicia, y ningún orden ni ningún concepto hacen justicia a su propia pretensión» (Adorno y Horkheimer, 1966: 26).

7. Naturalmente, un pensamiento que actúa movido por estas tesis siempre podrá ser acusado a la par de subjetivismo evaluativo -ya que su papel, en vez de en levantar acta de lo que acaece, consiste en sopesarlo a la luz de su contingencia-, y de idealismo normativo - pues juzga lo que acaece en términos que entrañan su reemplazo

2 La confianza en la libertad es, pese a todo, condición sine qua non de la crítica, que sin ella pierde, literalmente, el suelo en que apoyarse. 
por sus posibilidades mejoradas-. La razón crítica, es cierto, no es la razón empírica, ni la instrumental, y sus alegatos nunca salen indemnes del reproche de gratuidad, cuando no de fatuidad, especulativa. Sin embargo, precisamente porque se quiere racional, la razón crítica reivindica su derecho a hacerse oír: para sus defensores, el concepto mismo de Razón tiene su origen en un juicio de valor, y el concepto de verdad no puede separarse del valor de la razón (Marcuse, 1968: 249). No cabe imaginar, por lo demás, modo más cauto de manejar el valor que el de la razón crítica, la cual oscila entre la repugnancia a asignarle referentes positivos y la necesidad de reconocer su existencia: «la teoría adecuada reside en un análisis penetrante y crítico de la realidad histórica, no en algo así como en un esquema de valores abstractos del que uno se asegure que está fundamentado concreta y ontológicamente (...) Sólo se puede investigar los valores desvelando la praxis histórica que los destruye» (Horkheimer, 1966: 49; 1971: 132).

8. El pensamiento crítico, que rechaza, en suma, la indiferencia, procura asentarse en complicado equilibrio racional a horcajadas de la historia y de su falta de racionalidad. Y nada sería menos justo que subestimar a la razón crítica arguyendo que se trata del patrimonio de una casta de filósofos recluidos tras los balcones de su confortable residencia universitaria. Piensan críticamente todos los que, en el marco de sus respectivas disciplinas, rehúsan aceptar el universo dado de los hechos como norma final de validez; entre los cuales se cuentan hoy no pocos profesionales de la semiótica. Así ocurre con un sector de los representantes del análisis del discurso, quienes no vacilan en declarar, en sus más recientes programas, que su labor no debería permanecer descriptiva ni neutral, pues el interés que la guía es el de actuar como diagnóstico linguiístico que haga posible descubrir y desmistificar los mecanismos de la manipulación, del prejuicio, de la discriminación y de la demagogia semióticas; mecanismos que hay que volver explícitos y transparentes, lo que supone una toma de posiciones por parte del investigador (Wodak, 1990: 127). T. A. Van Dijk no deja dudas al respecto: «Más allá de la descripción o de las aplicaciones superficiales, la ciencia crítica en cada dominio propone otros interrogantes, tales como los de la responsabilidad, los intereses y la ideología. En lugar de centrarse en problemas puramente teóricos o académicos, arranca de los problemas sociales principales, y por tanto escoge la perspectiva de los que sufren más, analizando críticamente a aquellos que ocupan el poder, a aquellos que son responsables y a aquellos que tienen los medios y la posibilidad de resolver los problemas. Tan simple como eso» (Van Dijk, 1990: 128). 
9. Al tono y al contenido de este fragmento, no muy frecuentes en el campo de la ciencia, acaso pueda imputárseles un deje de redentorismo intelectual, o al menos una cierta candidez en cuanto a la competencia para intervenir sobre la realidad social que parece conceder a la siempre minoritaria práctica científica crítica. Pero tampoco debería olvidarse que la semiótica ha estado desde sus comienzos marcada por el muy particular carácter de su objeto, el sentido, saturado de toda suerte de implicaciones colectivas. Tanto es así que a lo largo de su historia como disciplina abundan los pronunciamientos, declarados o subrepticios, acerca del ineludible papel político, en la acepción más general, del ejercicio metadiscursivo de la semiótica. Ch. Morris, por ejemplo, iniciaba su obra mayor observando que investigar la naturaleza de los signos era mucho más que una simple práctica científica volcada hacia la obtención de menudos resultados acumulativos y verificables. Según él, la semiótica facilitaba comprender, de manera participativa, los principales problemas culturales y sociales. Morris, de hecho, asignó a los estudios semióticos un franco desempeño político al servicio de los regímenes democráticos y en contra del totalitarismo: tomar parte en un proceso educador de individuos socialmente autónomos, dotándoles de la suficiencia para analizar críticamente los ininterrumpidos flujos de signos que en adelante constituirían su entorno vital. El autor norteamericano, que consideraba lo social como una comunidad de símbolos, atribuía a la semiótica el cometido de velar por la organización racional de los símbolos comunitarios (Morris, 1962: 9, 267). Más cerca del momento presente, U. Eco ve también en la semiótica una forma de práctica a la que se subordina la estructura teórica, y precisa su emplazamiento epistemológico mediante lo que llama el «principio de indeterminación» — que nosotros preferiríamos llamar «de interrelación dialéctica»-: siendo la significación y la comunicación funciones sociales de las que depende el desarrollo de la cultura, dice Eco, significar la significación o comunicar sobre la comunicación tienen que influir sin falta en el universo del significar y del comunicar. Eco pertenece al grupo de autores para los cuales la encarecida neutralidad de las investigaciones puede fácilmente trocarse en coartada de una rutina valorativa que no confiesa de buena gana sus valores, aunque a las denuncias de las otras teorías prefiere la explanación de las actitudes de la suya. Propone así una semiótica concebida como crítica social, consciente en todo momento de que, si producir signos es en sí mismo una fuerza social, también la teoría semiótica desencadena fuerzas sociales, y entra necesariamente en el conflicto perpetuo de los distintos poderes sociales (1977: 60, 425). 
Pero sólo en una recopilación de ensayos sobre los medios de comunicación de masas impostará Eco a la pesquisa semiótica, de modo abierto y redundante, en tal tesitura: «Desde los sofistas, desde Sócrates, desde Platón, el intelectual hace política con su discurso (...) Comprender los mecanismos de lo simbólico a través de los cuales nos movemos significa hacer política. No comprenderlos conduce a practicar una política equivocada» $(1986: 8,294)$.

10. Luego la imagen que de la semiótica reenvían las anteriores ideas es la de un empeño que, a una conciencia más o menos aguda de sus limitaciones, añade el deseo de ser útil, de servir para algo mejor o peor determinado. De un empeño a buen seguro un poco autocomplaciente en sus mismos ribetes de ingenuidad, pero que tiene al menos el mérito de proponerse superar el estatuto positivista de neutral práctica atesoradora y autocorrectiva de saberes. Pues este último estatuto añade, a su manifiesto candor, una cierta dosis de mala fe; es decir, de interés denegado públicamente como tal interés.

11. Dicho esto, tanto el poner en duda la impecabilidad subjetiva y objetiva de la ciencia neutral como el sugerir que la semiótica participa activamente en la producción social del sentido desde el instante en que la somete a análisis, ni son obvios ni pueden evitar que tras ellos se levante una densa tolvanera de cuestiones por resolver. Sin ir más lejos, la misma suficiencia de la semiótica para hacer crítica de la cultura dista mucho de imponerse con una certidumbre incontestable. La dificultad mayor con que se enfrenta toda práctica cognoscitiva que, originándose en el propio eje de coordenadas ideológicas de un sistema cultural dado, ambicione alejarse de allí racionalmente, se reduce a saber si tal ejercicio de distanciamiento es de verdad capaz de generar una crítica política, y no solamente descriptiva. La respuesta que a ello dio R. Barthes tan temprano como en 1969 echa un jarro de agua fría sobre las optimistas hipótesis de Morris y de Eco: nadie, según él, habría logrado jamás forjar una crítica no cortada de su contexto de producción, pero que reaccionase contra él desde su interior, transformándolo genuinamente como un fermento negativo; para R. Barthes, la crítica política y la crítica cultural estaban condenadas a no encontrarse nunca (1969: 98). Y no parece temerario suponer que es la más o menos clara conciencia de las dificultades del pensamiento para independizarse de sus condiciones de partida la causa de que no pocos análisis semióticos, y sobre todo los que estudian los productos culturales de los medios de masas, estén tan frecuentemente repletos de denuncias políticas, cuyos alardes no son sino el reverso de una 
angustiosa inseguridad en sí mismas. Resulta cómodo, en efecto, reconocer a la semiótica, de entrada y sin aclaraciones, una misión ritual, mágica y redentora, funesta para las sutiles e insidiosas modalidades de la manipulación comunicativa. Pecado de hybris que a menudo cometen quienes han hecho de ella su único horizonte intelectual o profesional, y que por eso incurren en la ceguera para lo ajeno o en la sobreestimación de lo propio distintivas de los hiperespecialistas. De ahí que aquellos que también trabajan sobre documentos culturales, pero sin tenerse por propietarios del secreto código de acceso tecnológico al texto, ni por detentadores de la última palabra sobre su sentido y su ratio essendi, dejen a veces que su mirada sobre los practicantes de la semiótica, esa «ciencia milagrosa» (Faye, 1974: 38), se cargue de ironía. Ironía condescendiente de la que se hace no menos merecedor el semiólogo cuando invoca a los dioses tutelares del valor y de la certera comprensión de los fines: ¿es que quizá M.Weber se equivocaba al reiterar sin desmayo que una cosa son los juicios científicos, sujetos a control y verificación lógicas, y otra los juicios evaluativos, en última instancia indecidibles, y objetos todo lo más de especulación metafísica? (Weber, 1992: 365-433). O, dicho de otro modo, de situarse al comienzo de las investigaciones un llamamiento a la recta actitud ética o política, ¿no correrá el esfuerzo analítico de la semiótica el albur de oponer a la ideología que analiza una pura y simple forma de contraideología, que el lector deberá asumir irreflexivamente como mejor que la analizada sólo porque el semiótico se autoinviste mensajero de la razón crítica, o emancipadora, o incluso universal?

12. Espesas dudas de las que no es fácil librar a una disciplina, repitámoslo, en extremo sobrecargada de implicaciones y de contradicciones. Con todo, tampoco pensamos que disminuir la tensión entre el ser y el deber ser, entre la constatación neutral de los hechos y el enjuiciamiento comprometido que los transciende, pase por una renuncia desafiante, como la del mismo R. Barthes, a conseguir el estatuto de ciencia para la semiótica ni siquiera aunque a la ciencia se le impute buena parte de culpa en la «alienación del saber» contemporánea (Barthes, 1978: 36; 1984: 55). Pues la crítica del discurso científico, cuando se lleva a cabo desde una exterioridad total respecto de él, y se adorna además con las ínfulas de un intransigente radicalismo político, gira sin pausa en torno a su propio eje incriminatorio y deja intacto lo que debería ser su objeto, la epistemología de la ciencia. P. Bourdieu ya ha desmontado de sobra, y sin piedad, las que denomina «estrategias ideológicas disfrazadas de tomas de postura epistemológicas», características de quienes, ocupando en el campo de la ciencia una posición domina- 
da, y poseyendo un capital científico reducido, intentan hacer admitir como buenas sus actitudes anti o a-científicas gracias al descrédito político con el que cubren a las opciones de las autoridades científicas dominantes. Los que así actúan, apostilla Bourdieu, elevan a la categoría de revolución científica toda revolución contra el orden científico establecido: hacen como si bastara que una «innovación» sea excluida de la ciencia oficial para que pueda considerarse científicamente revolucionaria. A ello hay que replicar que el radicalismo epistémico, la firme voluntad de combatir el conformismo lógico de la inteligencia y la petrificación de los axiomas y procedimientos de las prácticas científicas preponderantes, no debe confundirse con la denuncia política global de la ciencia, del mismo modo que la explicitación de los apuros por los que atraviesa la weberiana teoría de la neutralidad en ciencias sociales poco tiene en común con una inoportuna reviviscencia moralizadora del humanismo de la tradición letrada (Althusser, 1976: 39; Bourdieu, 1976: 104; 1994: 102). Se diría, antes bien, que la tarea que las disciplinas críticas tienen por delante consiste en redefinir racionalmente los criterios de la cientificidad, tomando en cuenta la ineludible existencia de valores y de arbitrios ideológicos previos al comienzo de cualesquiera descripción y análisis, así como lo necesario de introducir entre las condiciones de ejercicio de la ciencia una cierta idea declarada de su finalidad, para que las prácticas científicas no se conviertan en una frenética carrera circular de obstáculos en la que sólo se premia el escasamente racional más difícil todavía.

13. Los diversos modelos de investigación que hoy conviven en el fragmentado espacio de la semiótica deben mucho al paradigma aislante-inmanente. Aunque no toda la herencia por ellos recibida es desdeñable, acaso deberían trabajar más para adquirir ese componente de autoconciencia que pueda convertirlos en instrumentos de una genuina crítica de la cultura. Pues es de esta última labor de donde procede la más amplia relevancia humana del estudio de los signos.

\section{Referencias bibliográficas}

Adorno, TH.W. y HorkHEIMER, M. (1966). Sociológica. Madrid: Taurus. Althusser, L. (1976). Positions. París: Éditions Sociales.

BARTHES, R. (1969). «Un cas de critique culturelle». Communications 14, 9799. 
- (1978). Leçon. París: Seuil.

- (1984). Le bruissement de la langue. París: Seuil.

Bettetini, G. (1977). Producción significante y puesta en escena. Barcelona: Gustavo Gili.

BOURDIEU, P. (1976). «Le champ scientifique». Actes de la recherche en sciences sociales 2-3, 88-104.

- (1994). Raisons pratiques. Sur la théorie de l'action. París: Seuil.

COURTÈs, J. (1976). Introduction à la sémiotique narrative et discursive. París: Hachette.

Eco, U. (1977). Tratado de semiótica general. Barcelona: Lumen.

- (1986). La estrategia de la ilusión. Barcelona: Lumen.

FAYE, J. P. (1974). Los lenguajes totalitarios. Madrid: Taurus.

HORKHEIMER, M. (1971). Teoría crítica. Barcelona: Barral.

JAMESON, F. (1989). Documentos de cultura, documentos de barbarie. La narrativa como acto socialmente simbólico. Madrid: Visor.

MARCUSE, H. (1968). El hombre unidimensional. Barcelona: Seix Barral.

Morris, CH. (1962). Signos, lenguaje y conducta. Buenos Aires: Losada.

PASSERON, J.-C. (1991). Le raisonnement sociologique. L'espace non-poppérien du raisonnement naturel. París: Nathan.

PÊcheuX, M. (1975). Les vérités de La Palice. Linguistique, sémantique, philosophie. París: Maspéro.

- (1978). Hacia el análisis automático del discurso. Madrid: Gredos.

Petitot, J. (1985). Morphogénèses du sens. París: PUF.

RUPRECHT, H.G. (1984). «Savoir et littérature: doxa historique/épistemé scientifique». Degrés, 39-40, m-m 12.

VAN DIJK, T.A. (1990). «The future of the field: Discourse analysis in the 1990s». Text 10: 1/2, 133-156.

VERÓN, E. (1984). «Ideología y comunicación de masas: la semantización de la violencia política». En Lenguaje y comunicación social, 133-191. Buenos Aires: Nueva Visión.

- (1987). La sémiosis sociale. Fragments d'une théorie de la discursivité. Vincennes: Presses Universitaires.

WeBER, M. (1992). Essais sur la théorie de la science. París: Plon.

WODAK, R. (1990). «Discourse analysis: Problems, findings, perspectives». Text 10: 1/2, 125-132.

ZIMA, P. (1994). La déconstruction. Une critique. París: PUF. 